\title{
Outbreak of pulmonary Pseudomonas aeruginosa and Stenotrophomonas maltophilia infections related to contaminated bronchoscope suction valves, Lyon, France, 2014
}

M Guy ${ }^{1}$, P Vanhems ${ }^{12}$, C Dananché ${ }^{1}$, M Perraud ${ }^{3}$, A Regard ${ }^{1}$, M Hulin ${ }^{1}$, 0 Dauwalder ${ }^{4}$, X Bertrand ${ }^{5}$, J Crozon-Clauzel 6 , B

Floccard 7 , L Argaud 8 , P Cassier ${ }^{3}$, T Bénet ${ }^{12}$

1. Infection Control and Epidemiology Unit, Edouard Herriot Hospital, Hospices Civils de Lyon, Lyon, France

2. Laboratoire des Pathogènes Emergents - Fondation Mérieux, Centre International de Recherche en Infectiologie (CIRI), Inserm U1111, CNRS UMR5308, ENS de Lyon, UCBL1, Lyon, France

3. Environmental Microbiology Laboratory, Edouard Herriot Hospital, Hospices Civils de Lyon, Lyon, France

4. Laboratory of Microbiology, Biology and Pathology Center East, East Hospital Complex, Hospices Civils de Lyon, Bron, France

5. Infection Control Unit, Centre Hospitalier Régional et Universitaire de Besançon, Besançon, France

6. Intensive Care Unit, Edouard Herriot Hospital, Hospices Civils de Lyon, Lyon, France

7. Surgical Intensive Care Unit, Edouard Herriot Hospital, Hospices Civils de Lyon, Lyon, France

8. Medical Intensive Care Unit, Edouard Herriot Hospital, Hospices Civils de Lyon, Lyon, France

Correspondence: Thomas Bénet (thomas.benet@chu-lyon.fr)

Citation style for this article:

Guy M, Vanhems P, Dananché C, Perraud M, Regard A, Hulin M, Dauwalder O, Bertrand X, Crozon-Clauzel J, Floccard B, Argaud L, Cassier P, Bénet T. Outbreak of pulmonary Pseudomonas aeruginosa and Stenotrophomonas maltophilia infections related to contaminated bronchoscope suction valves, Lyon, France, 2014. Euro Surveill. 2016;21(28): pii=30286. DOI: http://dx.doi.org/10.2807/1560-7917.ES.2016.21.28.30286

Article submitted on 28 September 2015 / accepted on 29 March 2016 / published on 14 July 2016

In April 2014, pulmonary Pseudomonas aeruginosa and Stenotrophomonas maltophilia co-infections potentially related to bronchoscopic procedures were identified in the intensive care units of a university hospital in Lyon, France. A retrospective cohort of 157 patients exposed to bronchoscopes from 1 December 2013 to 17 June 2014 was analysed. Environmental samples of suspected endoscopes were cultured. Bronchoscope disinfection was reviewed. Ten cases of pulmonary $P$. aeruginosa/S. maltophilia co-infections were identified, including two patients with secondary pneumonia. Eight cases were linked to bronchoscope A1 and two to bronchoscope A2. Cultures deriving from suction valves were positive for $P$. aeruginosa/S. maltophilia. Exposure to bronchoscopes $A_{1}$ and $A_{2}$ was independently coupled with increased risk of co-infection (adjusted odds ratio $(\mathrm{aOR})=84.6 ; 95 \%$ confidence interval (CI): 9.3-771.6 and aOR $=11.8$, $95 \% \mathrm{Cl}: 1.2-121.3)$. Isolates from suction valves and clinical samples presented identical pulsotypes. The audit detected deficiencies in endoscope disinfection. No further cases occurred after discontinuation of the implicated bronchoscopes and change in cleaning procedures. This outbreak of pulmonary $P$. aeruginosa/S. maltophilia co-infections was caused by suction valve contamination of two bronchoscopes of the same manufacturer. Our findings underscore the need to test suction valves, in addition to bronchoscope channels, for routine detection of bacteria.

\section{Introduction}

Outbreaks and pseudo-outbreaks associated with bronchoscopic procedures have been reported in the literature [1-3]. The microorganisms most commonly implicated in these outbreaks are Pseudomonas aeruginosa [4-8], Mycobacterium tuberculosis [9,10], and $M$. chelonae $[11,12]$. In most cases, only a single microorganism is identified, infection by several microorganisms is less frequent [13,14]. Contamination in past outbreaks had various causes, including water from automated endoscope reprocessors $[11,15]$, damaged [7] or defect bronchoscopes $[6,13,16]$, misuse of connectors, deficiencies in the cleaning process and, much less frequently, contamination of suction valves $[17,18]$. To reduce the risk of nosocomial infections from bronchoscopic procedures, national bronchoscopy guidelines have been established in several countries, including France [19-24]. Despite the increasing experience of bronchoscopic teams, up-to-date guidelines and outbreak reports, patients might still be exposed to contaminated bronchoscopes.

In April 2014, we were alerted to two cases of early-onset pneumonia with $P$. aeruginosa and Stenotrophomonas maltophilia in young and immunocompetent trauma patients, after exposure to the same bronchoscope in Edouard Herriot Hospital (Hospices Civils de Lyon, Lyon, France). Here, we report the results of this outbreak investigation and the impact of control measures. 


\section{FIGURE 1}

Epidemic curve of Pseudomonas aeruginosa- and Stenotrophomonas maltophilia-positive cultures isolated from respiratory samples of patients exposed or not exposed to bronchoscopes, France, November 2013August $2014(\mathrm{n}=15)$

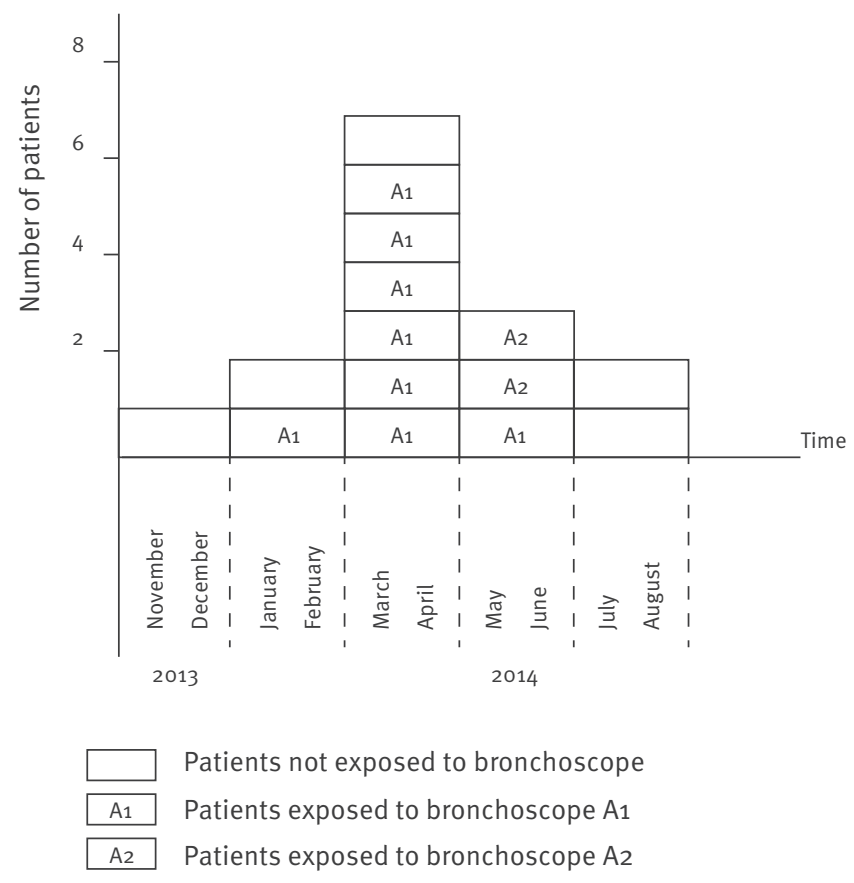

\section{Methods}

\section{Setting}

Edouard Herriot Hospital is a 900-bed university-affiliated hospital from Hospices Civils de Lyon in Lyon, France, with four intensive care units (ICUs) accounting for 62 beds overall (ICUs \#A, \#B, \#C and \#D). Each year, more than 350 bronchoscopic and 2,000 cleaning procedures are performed in the hospital. In 2014, eight bronchoscopes were used in the endoscopy suite: three of the same model from manufacturer $A$ (bronchoscopes $A_{2}, A_{2}, A_{3}$ ) and five from manufacturer $B$ (bronchoscopes B1, B2, B3, B4, B5). These bronchoscopes were deployed in ICUs, operating rooms or other care units.

\section{Bronchoscope cleaning procedures}

Bronchoscope cleaning and storage are centralised in ICU \#C. Immediately after use, external bronchoscope surfaces are wiped with compresses and channels flushed with water. The bronchoscopes are taken to ICU \#C for cleaning, as soon as possible, by authorised personnel, in accordance with a standardised local protocol adapted from French national recommendations [22]. A tightness test is performed before the bronchoscopes are soaked in detergent-disinfectant (Phagoclean NH4, Laboratoire Phagogène, Christeyns, France) and cleaned manually by wiping the outer surface, brushing and flushing internal channels. Each removable component is removed and cleaned. After rinsing, the bronchoscopes are processed in an automated endoscope reprocessor (Soluscope Series 3 PA, Soluscope, Aubagne, France) with disinfectant (Soluscope P), additive (Soluscope A) and detergent (Soluscope C+). Finally, after drying, the bronchoscopes are kept in an aseptic storage cabinet (Medi 72, Medinorme, La Seyne-sur-Mer, France). Standardised forms are completed for each procedure to maintain traceability.

\section{Outbreak investigations}

In April 2014, two cases of early-onset pneumonia with $P$. aeruginosa/S. maltophilia in young, not immunocompromised trauma patients in ICU \#C were reported to the Infection Control Unit. These patients were exposed to the same bronchoscope (A1). An investigation was launched. In June 2014, two further pulmonary $P$. aeruginosa/S. maltophilia co-infections in patients exposed to bronchoscope $\mathrm{A} 2$ were encountered in ICU \#B. An additional investigation was conducted with a retrospective cohort of patients exposed to bronchoscopes from 1 December 2013 to 17 June 2014 in Edouard Herriot Hospital and a nested case-control study.

Cases were defined as patients exposed to bronchoscopes between 1 December 2013 and 17 June 2014, with $P$. aeruginosa/S. maltophilia-positive cultures isolated from clinical respiratory samples. We included only positive cultures from broncho-alveolar lavage, tracheobronchial aspiration or plugged telescoping catheter (Combicath), obtained during or after the bronchoscopic procedure. Sputum samples were not considered. Controls were defined as patients exposed to bronchoscopes in the same period but without positive respiratory sample cultures of the microorganisms found on bronchoscopes, namely P. aeruginosa, S. maltophilia, Klebsiella pneumoniae, Enterobacter cloacae or Achromobacter xylosoxidans. For the epidemic curve, the period of interest began on 1 November 2013.

Patients exposed to bronchoscopes were identified from standardised, prospectively collected forms detailing bronchoscope use. Clinical sample results were obtained from the microbiological laboratory (according to European guidelines [25]) for patients exposed to bronchoscope for whom a microbiological sample was available, and medical case records were reviewed. Bronchoscope cleaning processes were audited by the Infection Control Unit. Prospective surveillance was implemented starting from the first investigation, as soon as the infection control team was informed. Every day, a member of the infection control unit was looking for new cases, checking results of cultures isolated from respiratory samples from patients in Edouard Herriot Hospital.

\section{Environmental investigation}

According to French guidelines [24], samples from suspected bronchoscope channels were taken by two authorised personnel, after cleaning and at least six 
Pulsed-field gel electrophoresis of Pseudomonas aeruginosa isolates from clinical $(\mathrm{n}=8)$ and environmental (n = 6) samples, France, November 2013-August 2014

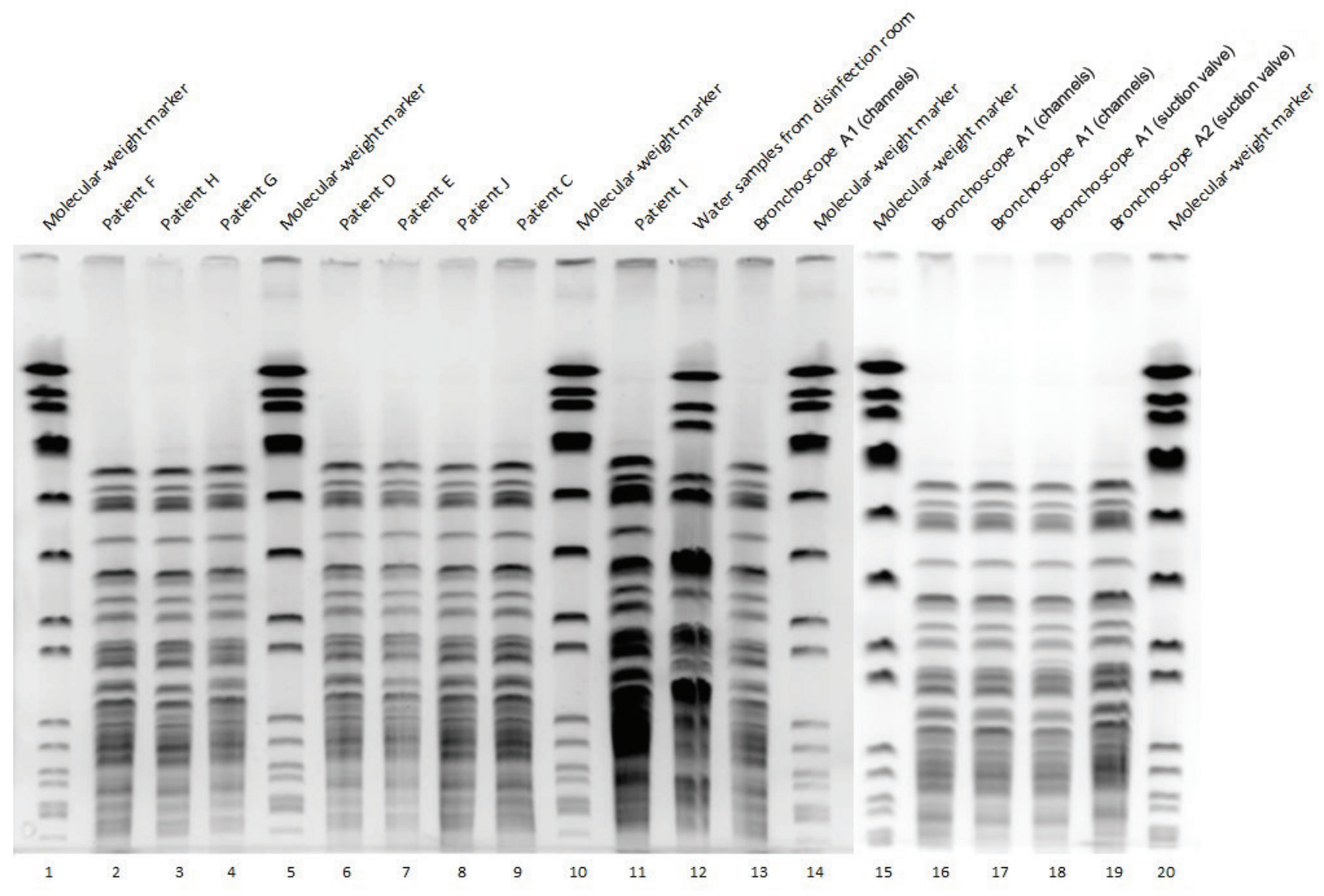

Macrorestriction profiles of total DNA from clinical and environmental isolates were acquired by pulsed-field gel electrophoresis (PFGE) on a CHEF-DR III unit (Bio-Rad, Hercules, US). Isolates of $P$. aeruginosa from clinical samples (patients C, D, E, F, G, H, I and J) were identical to isolates from channels and suction valve of bronchoscope A1 and to isolates from the suction valve of bronchoscope A2, but differed from tap water isolates from the disinfection room. Staphylococcus aureus NCTC 8325 (with Smal as restriction enzyme) was used as a reference (molecular weight marker), and PFGE patterns were analysed visually.

hours of storage. Sixty $\mathrm{mL}$ of Pharmacopeia dilution solution with antimicrobial inactivators (DNP buffer, AES Chemunex, bioMérieux, Marcy l'Etoile, France) were flushed into proximal ports and collected in sterile cups at the distal end of the operating channel. As the first set of cultures from bronchoscope channel samples were negative, bronchoscope suction valves and biopsy valves from suspected bronchoscopes were sampled.

In addition, surface samples from the aseptic storage cabinet for bronchoscopes, water samples from automated endoscope reprocessors and tap water samples from ICU \#C were cultured.

\section{Molecular typing}

Macrorestriction profiles of total DNA from clinical and environmental isolates were acquired by pulsedfield gel electrophoresis (PFGE) on a CHEF-DR III unit
(Bio-Rad, Hercules, United States (US)) [26]. Dral and $X b a l$ served as restriction enzymes for $P$. aeruginosa and $S$. maltophilia, respectively. We ensured that the gels were comparable by including Staphylococcus aureus NCTC 8325 (with Smal as restriction enzyme) as a reference, and PFGE patterns were analysed visually.

\section{Statistical analysis}

In the nested case-control study, all exposures to bronchoscopes were considered to be potential risks. Other potential risk factors were unit, patient age, sex and number of bronchoscopic procedures per patient. To identify characteristics linked with the risk of being a case, categorical variables were compared by chisquare test, and continuous variables by the MannWhitney $U$ test. All tests were two-tailed. A p value of $<0.05$ was considered significant. Univariate and multivariate logistic regression was undertaken with Stata 11.0 software (StataCorp, College Station, US). 
Pulsed-field gel electrophoresis of Stenotrophomonas maltophilia isolates from $(\mathrm{n}=8)$ and environmental $(\mathrm{n}=3)$ samples, France, November 2013-August 2014

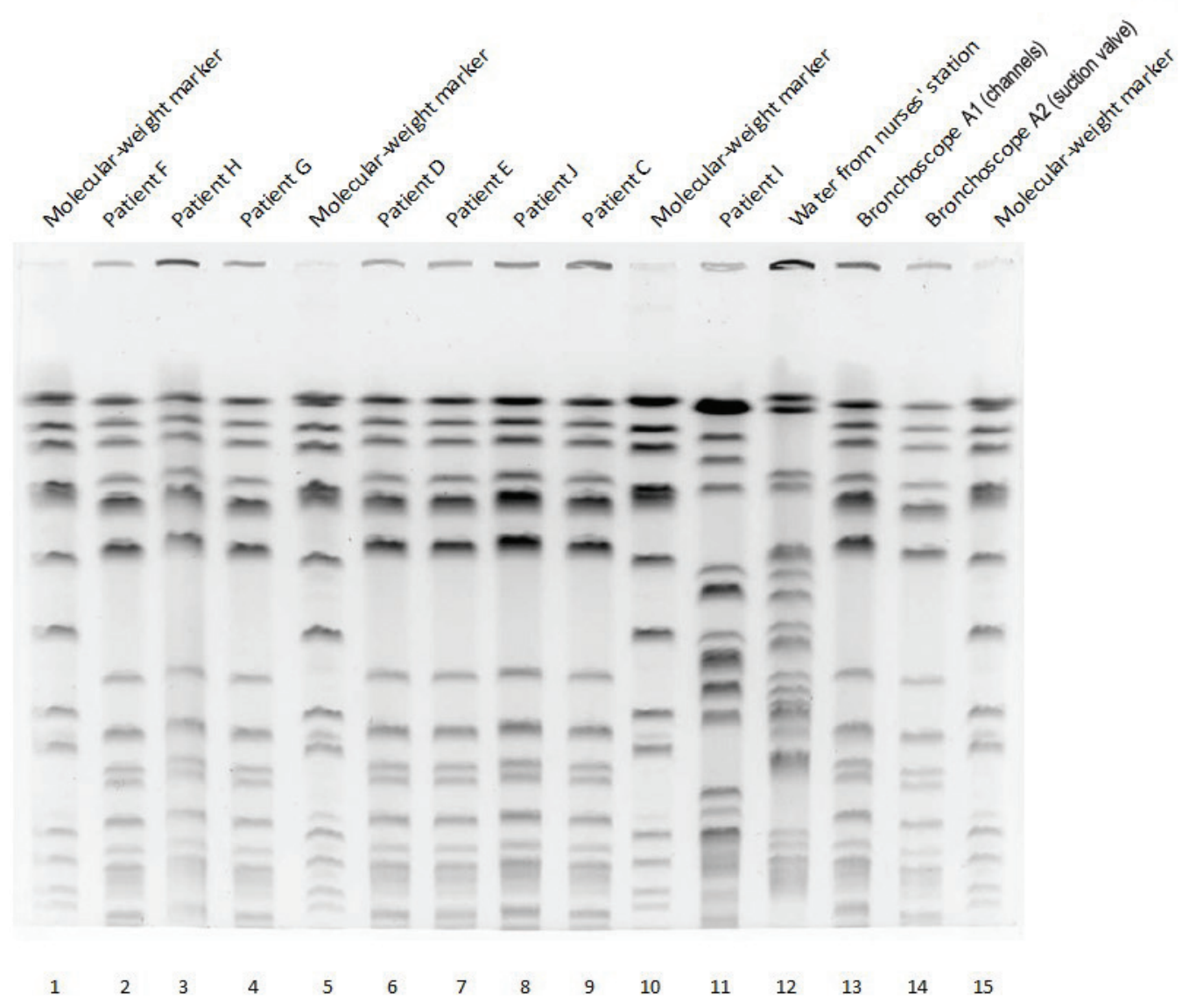

Macrorestriction profiles of total DNA from clinical and environmental isolates were acquired by pulsed-field gel electrophoresis (PFGE) on a CHEF-DR III unit (Bio-Rad, Hercules, US). Isolates of S. maltophilia isolates from clinical samples (except for patient I) were identical to isolates from the suction valve of bronchoscope $A_{2}$ and to isolates from the channels of bronchoscope $A_{1}$, but differed from tap water isolates found in the nurses' station. Staphylococcus aureus NCTC 8325 (with Smal as restriction enzyme) was used as a reference (molecular weight marker), and PFGE patterns were analysed visually.

\section{Results}

Between 1 December 2013 and 17 June 2014, 157 patients were exposed to at least one bronchoscope, and 216 bronchoscopic procedures were undertaken. Median age was 62 years (interquartile range (IQR): 49-73 years), and 111 patients (71\%) were male. Overall, 10 patients had $P$. aeruginosa/S. maltophiliapositive cultures isolated from respiratory sampling; 35 patients had at least one respiratory sample with P. aeruginosa, S. maltophilia, K. pneumonia, E. cloacae or A. xylosoxidans, but did not fulfil the criteria of the case definition, and the respiratory samples of 112 patients were negative for all of these pathogens. The 10 cases identified were all men, with a median age of 52 years (IQR: $23-67$ years) (Table 1 ), three were previously hospitalised and nine were intubated during their ICU stay. Among them, two patients had secondary pneumonia, nine and 11 days after bronchoscopy.
Three cases died during ICU stay and their deaths were not related to bronchoscope contamination. Eight cases were associated with bronchoscope $\mathrm{A}_{1}$ and two cases with bronchoscope A2. During the outbreak, the attack rate among cases exposed to bronchoscopes was $9.4 \%$ between February and June 2014 compared with $\% \%$ between December 2013 and January 2014 (p<0.05); five patients had $P$. aeruginosa/S. maltophilia positive respiratory samples but had not been exposed to a bronchoscope (Figure 1).

We compared exposed patients co-infected with P. aeruginosa and S. maltophilia $(\mathrm{n}=10)$ to non-infected patients $(n=112)$ during the outbreak period (Table 2). Univariate analysis disclosed that exposure to bronchoscope $A_{1}$ or $A_{2}$, hospitalisation unit and number of bronchoscopic procedures per patient were associated with increased risk of being a case. After multivariate 


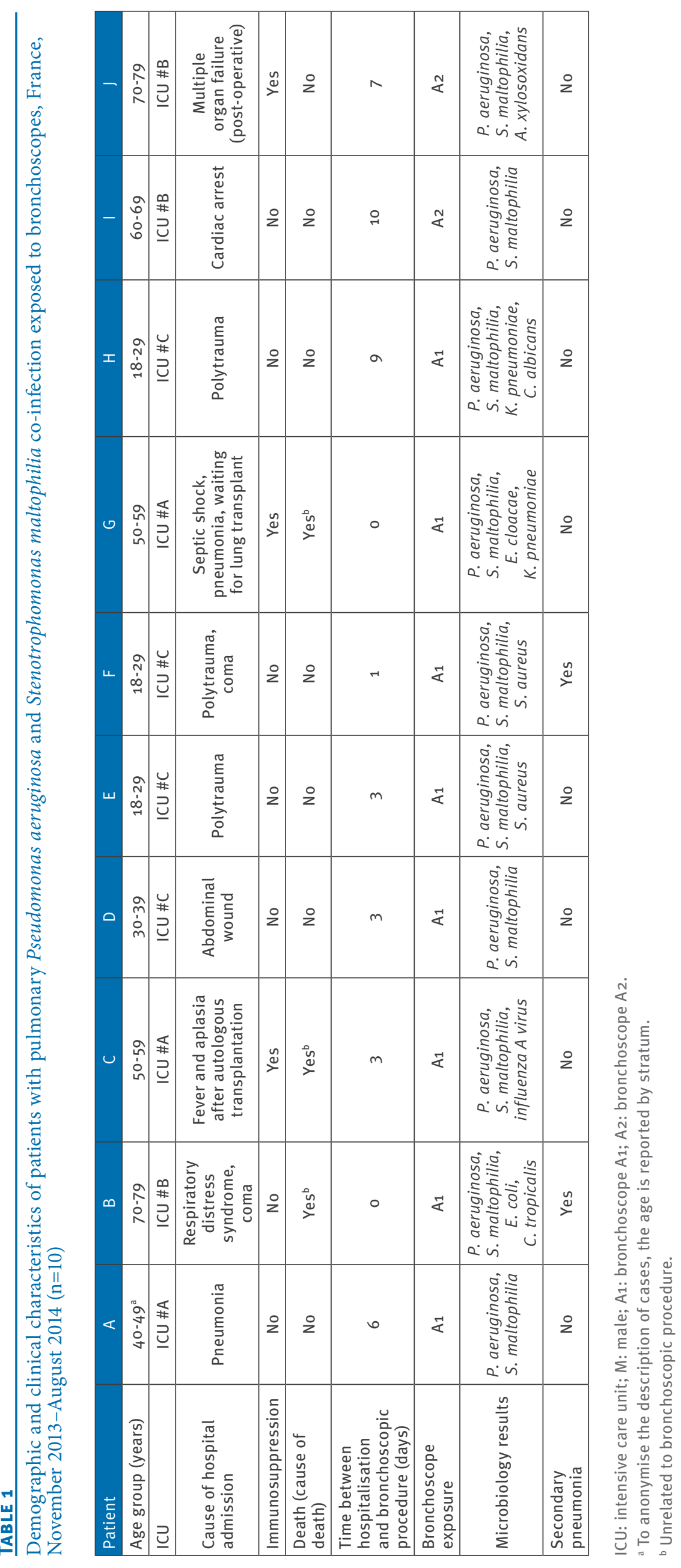


TABLE 2

Factors associated with the risk of Pseudomonas aeruginosa and Stenotrophomonas maltophilia co-infection, France, November 2013-August $2014(\mathrm{n}=122)$

\begin{tabular}{|c|c|c|c|c|}
\hline Characteristics & $\begin{array}{c}\mathrm{Pa} / \mathrm{Sm} \text { co-infection } \\
\mathrm{n}(\%)\end{array}$ & $\begin{array}{c}\text { Non-infected }{ }^{\mathrm{a}} \\
\mathrm{n}(\%)\end{array}$ & $\mathrm{p}$ & $\begin{array}{l}\text { Crude odds ratio } \\
(95 \% \mathrm{Cl})\end{array}$ \\
\hline Total & 10 & 112 & & \\
\hline Age (years) & $52(23-67)^{b}$ & $62(49-72)^{b}$ & 0.07 & $0.96(0.92-1.0)^{b, c}$ \\
\hline Sex (female) & $0(0)$ & $39(35)$ & 0.02 & NE \\
\hline \multicolumn{5}{|c|}{ Bronchoscope exposure $^{d}$} \\
\hline Bronchoscope $A_{1}$ & $8(80)$ & $9(8)$ & $<0.001$ & $45.8(8.4-248.7)^{\mathrm{e}}$ \\
\hline Bronchoscope A2 & $4(40)$ & $16(14)$ & 0.03 & $4.0(1.02-15.8)^{\mathrm{e}}$ \\
\hline Bronchoscope $A_{3}$ & $2(20)$ & $17(15)$ & 0.69 & $1.4(0.3-7.2)^{\mathrm{e}}$ \\
\hline Bronchoscope B1 & o (o) & $0(0)$ & NA & NE \\
\hline Bronchoscope B2 & $1(10)$ & $24(21)$ & 0.39 & $0.4(0.05-3.4)^{\mathrm{e}}$ \\
\hline Bronchoscope B3 & $2(20)$ & $25(22)$ & 0.86 & $0.9(0.2-4.4)^{\mathrm{e}}$ \\
\hline Bronchoscope B4 & $0(0)$ & $27(24)$ & 0.08 & NE \\
\hline Bronchoscope B5 & $0(0)$ & $13(12)$ & 0.25 & NE \\
\hline \multicolumn{5}{|l|}{ Unit } \\
\hline Intensive care unit & $10(100)$ & $70(62)$ & 0.02 & NE \\
\hline Operating rooms & $0(0)$ & $30(27)$ & 0.06 & NE \\
\hline Other units & $0(0)$ & $12(11)$ & 0.28 & NE \\
\hline \multicolumn{5}{|c|}{ Number of bronchoscopic procedures } \\
\hline 1 & $5(50)$ & $95(85)$ & \multirow{2}{*}{0.006} & 1.0 (reference) \\
\hline$\geq 2$ & $5(50)$ & $17(15)$ & & $5.6(1.5-21.4)$ \\
\hline
\end{tabular}

NA: not applicable; NE: could not be estimated; Pa/Sm: Pseudomonas aeruginosa/Stenotrophomonas maltophilia.

a Patients for whom Pseudomonas aeruginosa, Stenotrophomonas maltophilia, Klebsiella pneumonia, Enterobacter cloacae or Achromobacter xylosoxidans could not be isolated from respiratory samples.

${ }^{\mathrm{b}}$ Median interquartile range.

c For one year older.

${ }^{\mathrm{d}}$ More than one exposure was possible.

${ }^{e}$ Compared with the absence of exposure to this particular endoscope.

analysis, exposure to bronchoscope $\mathrm{A}_{1}$ and bronchoscope A2 was independently associated with heightened risk of $P$. aeruginosa/S. maltophilia co-infection (adjusted odds ratio $(\mathrm{aOR})=84.6,95 \%$ confidence interval $(\mathrm{Cl}): 9.3-771.6$ and $\mathrm{aOR}=11.8,95 \% \mathrm{Cl}: 1.2-$ 121.3, respectively). No further cases occurred after sequestration of the two implicated bronchoscopes.

\section{Endoscopic and environmental cultures}

As soon as the first two cases with $P$. aeruginosa/S. maltophilia in patients exposed to bronchoscope $A_{1}$ were reported, the device was investigated and taken out of service. However, as bronchoscope channel samples were negative in bacteriological testing, we allowed it to be used again. Meanwhile, ICU \#C tap water was sampled. $P$. aeruginosa grew from one sample in the disinfection room, and $S$. maltophilia grew from one sample in the nurses' station. Contaminated washbasins were disinfected, and control samples were negative. Thus, contaminated tap water was deemed to be the potential source of infection. At that time, the source of contamination was considered to be controlled, and active surveillance was implemented.
However, in May 2014, another case of $P$. aeruginosa/S. maltophilia pneumonia attributed to bronchoscope $A_{1}$ was detected. Bronchoscope A1 was withdrawn from circulation and sent to the manufacturer for technical expertise. Bronchoscope channels and valves were sampled by the infection control team. Channel samples grew both $P$. aeruginosa and $S$. maltophilia, and the suction valve grew Burkholderia cepacia, E. cloacae, K. pneumonia and $P$. aeruginosa. The biopsy valve culture remained negative. The expert report noted that the suction valve had a porous seal. The environmental investigation was extended to the aseptic storage cabinet and water from automated endoscope reprocessors, but these sample cultures were negative.

In June 2014, two additional $P$. aeruginosa/S. maltophilia pneumonia cases were reported in patients exposed to bronchoscope A2 in ICU \#B; it was removed from use. Channel and biopsy valve samples were negative, but the suction valve grew $P$. aeruginosa and S. maltophilia. Sampling was extended to bronchoscope $A_{3}$, but channel and valve cultures were negative. Routine samples from the endoscopes of other 
brands were all negative for $P$. aeruginosa or S. maltophilia during the outbreak period.

\section{Molecular typing}

PFGE revealed that isolates of $P$. aeruginosa (Figures 2 and 3) from clinical samples (patients C, D, E, F, G, $\mathrm{H}, \mathrm{I}$ and $\mathrm{J}$ ) were identical to isolates from channels and suction valve of bronchoscope $A 1$ and to isolates from the suction valve of bronchoscope $A_{2}$, but differed from isolates obtained from tap water in the disinfection room. Similarly, S. maltophilia isolates from clinical samples (except for patient I) were identical to isolates from the suction valve of bronchoscope $A_{2}$ and to isolates from the channels of bronchoscope $A_{1}$, but differed from tap water isolates found in the nurses' station. Clinical isolates from patients A and B could not be recovered for typing.

\section{Bronchoscope cleaning processes}

Bronchoscope cleaning processes were audited by the Infection Control Unit with a standardised form. Some deficiencies were detected such as delays between endoscopy and cleaning. Moreover, the tightness test was not always performed before manual cleaning. However, these deficiencies were not specific to bronchoscopes from manufacturer A. Corrective actions were taken. Protocols were updated, traceability was improved, and single-use bronchoscopes were provided during the night and on-call duties in order to avoid latency between bronchoscopy and cleaning. As of 24 June 2016, no contamination of bronchosocope with $P$. aeruginosa/S. maltophilia has been identified, no new case related to bronchoscope exposure has occurred since bronchoscope disinfection was improved.

\section{Discussion}

From December 2013 to June 2014, an outbreak of $P$. aeruginosa/S. maltophilia co-infections was investigated in 10 patients undergoing bronchoscopy. These cases were related to two bronchoscopes of the same model from which $P$. aeruginosa/S. maltophilia were isolated from the suction valves. Clinical and contaminated bronchoscope isolates showed similar PFGE patterns. Two secondary pneumonia infections were identified among the cases. The respiratory samples may have been contaminated in the eight other cases, but antibiotic therapy was initiated for all patients and may have prevented the development of nosocomial pneumonia.

One of the key issues is to know how bronchoscope $A_{1}$ was contaminated. As environmental sources of contamination were excluded, it may have been tainted during a bronchoscopic procedure on a patient colonised or infected by $P$. aeruginosa/S. maltophilia. Persistent contamination was probably partially due to defective bronchoscope cleaning as some deficiencies were highlighted by the audit. Furthermore, the complexity of suction valve cleaning and disinfection compared to other bronchoscopes might have contributed to the event.

Detection of this outbreak may have been further delayed because there was no specific surveillance of patients exposed to bronchoscopes. Moreover, the source of contamination was found by extended bronchoscope sampling. Bronchoscope disinfection is routinely assessed by channel sampling, as recommended in French guidelines [24]. The first results of bronchoscope contamination detection were probably false negatives. This outbreak highlights the benefits of routinely testing suction valves to look for bacterial contamination of bronchoscopes. In case of suspected contamination, suction valves should be systematically tested. If contaminated, they should be removed and replaced or sterilised. This outbreak raises questions about the cleaning process for suction valves. Indeed, there is no consensus on whether single-use suction valves, high-level suction valve disinfection or sterilisation after manual cleaning should be preferred. The manufacturer confirmed the lack of recommendations for suction valve management. The expert report stated that the submitted suction valve had porous seals which increased the risk of contamination. Preventive replacement of suction valves should be considered.

Faced with the contamination of two bronchoscopes of the same model, within the same part (suction valves), we wonder about increased risks posed by these devices. We therefore reported the event to the French National Agency for Medicines and Health Products Safety (Agence nationale de sécurité du médicament et des produits de santé (ANSM)), where no other notifications concerning these bronchoscopes were filed. Disparities in the hospital's stock of bronchoscopes regarding brands or preventive maintenance and lack of preventive maintenance were probable contributing factors. The two bronchoscopes under investigation were bought in 2007 and 2008 and did not have preventive maintenance contracts with the manufacturer.

Other outbreaks or pseudo-outbreaks tied to suction valve contamination have been described, mostly before the 2000s, but they involved mycobacteriae [17,18]. Bronchoscope contamination by P. aeruginosa/S. maltophilia was reported in the investigation of a pseudo-outbreak in Baltimore, US in 2008 [27] and more recently, contamination by S. maltophilia was reported in the Netherlands [28].

Our investigations had some limitations. We did not find the index case, and the route of pathogen transmission from bronchoscopes $A_{1}$ and $A 2$ was not clearly identified. Transmission may have occurred through one secondary case exposed to both bronchoscopes, or perhaps through the connectors. Moreover, B. cepacia, E. cloacae and $K$. pneumonia were identified on one bronchoscope suction valve. Our case definition did not include patients with respiratory samples positive 
for these microorganisms. We may have underestimated the magnitude of the outbreak.

\section{Conclusion}

We investigated an outbreak of $P$. aeruginosa/S. maltophilia pulmonary infections caused by suction valve contamination of two bronchoscopes from the same manufacturer. While bronchoscope contamination might be attributed to deficiencies in bronchoscope cleaning processes, suction valves of these bronchoscopes have a particular design which may increase the risk of contamination; the manufacturer was informed in the process and they were cooperative. No further confirmed cases exposed to bronchoscope have been detected as at 24 June 2016. Our findings underscore the need to test not only bronchoscope channels but also suction valves regularly for routine detection of bacteria. The large number of patients worldwide who are exposed daily to bronchoscope examinations highlights the necessity for regular updates of guidelines, appropriate hygiene procedures and reporting new risks to improve patient safety.

\section{Acknowledgements}

We thank the staff of the intensive care units of Edouard Herriot Hospital (Lyon, France) for their valuable cooperation. We thank François Vandenesch for his valuable assistance in microbiological analysis.

\section{Conflict of interest}

None declared.

\section{Authors' contributions}

Marine Guy: performed epidemiological investigations, analysis, manuscript writing. Philippe Vanhems: project leader, performed epidemiological investigations, reviewed the manuscript. Cédric Dananché: performed epidemiological investigations, reviewed the manuscript. Pierre Cassier: performed environmental microbiologic analysis, reviewed the manuscript. Anne Regard: performed epidemiological investigations, reviewed the manuscript. Monique Hulin: performed epidemiological investigations, reviewed the manuscript

Olivier Dauwalder: performed microbiologic analysis, reviewed the manuscript. Xavier Bertrand: performed pulsedfield gel electrophoresis analysis, reviewed the manuscript. Jullien Crozon-Clauzel: participated in epidemiological investigation, reviewed the manuscript. Bernard Floccard: participated in epidemiological investigation, reviewed the manuscript. Laurent Argaud: participated in epidemiological investigation, reviewed the manuscript. Michel Perraud: performed epidemiological investigations, reviewed the manuscript. Thomas Bénet: project leader, performed epidemiological investigations, analysis and interpretation of results, manuscript writing.

\section{References}

1. Weber DJ, Rutala WA. Lessons from outbreaks associated with bronchoscopy. Infect Control Hosp Epidemiol. 2001;22(7):4038. DOI: $10.1086 / 501924$ PMID: 11583206
2. Weber DJ, Rutala WA. Lessons learned from outbreaks and pseudo-outbreaks associated with bronchoscopy.Infect Control Hosp Epidemiol. 2012;33(3):230-4. DOI: 10.1086/664495 PMID: 22314058

3. Mehta AC, Prakash UBS, Garland R, Haponik E, Moses L, Schaffner W, et al. American College of Chest Physicians and American Association for Bronchology consensus statement: prevention of flexible bronchoscopy-associated infection. Chest. 2005;128(3):1742-55. DOI: 10.1378/chest.128.3.1742 PMID: 16162783

4. Schelenz S, French G. An outbreak of multidrug-resistant Pseudomonas aeruginosa infection associated with contamination of bronchoscopes and an endoscope washerdisinfector.J Hosp Infect. 2000;46(1):23-30. DOI: 10.1053/ jhin.2000.0800 PMID: 11023719

5. Sorin M, Segal-Maurer S, Mariano N, Urban C, Combest A, Rahal JJ. Nosocomial transmission of imipenem-resistant Pseudomonas aeruginosa following bronchoscopy associated with improper connection to the Steris System 1 processor. Infect Control Hosp Epidemiol. 2001;22(7):409-13. DOI: 10.1086/501925 PMID: 11583207

6. Srinivasan A, Wolfenden LL, Song X, Mackie K, Hartsell TL, Jones HD, et al. An outbreak of Pseudomonas aeruginosa infections associated with flexible bronchoscopes. N Engl J Med. 2003;348(3):221-7. DOI: 10.1056/NEJMoa021808 PMID: 12529462

7. DiazGranados CA, Jones MY, Kongphet-Tran T, White N, Shapiro $M$, Wang YF, et al. Outbreak of Pseudomonas aeruginosa infection associated with contamination of a flexible bronchoscope. Infect Control Hosp Epidemiol. 2009;30(6):5505. DOI: 10.1086/597235 PMID: 19379099

8. Bou R, Aguilar A, Perpiñán J, Ramos P, Peris M, Lorente L, et al. Nosocomial outbreak of Pseudomonas aeruginosa infections related to a flexible bronchoscope. J Hosp Infect. 2006;64(2):129-35. DOI: 10.1016/j.jhin.2006.06.014 PMID: 16895738

9. Ramsey AH, Oemig TV, Davis JP, Massey JP, Török TJ. An outbreak of bronchoscopy-related Mycobacterium tuberculosis infections due to lack of bronchoscope leak testing.Chest. 2002;121(3):976-81. DOI: 10.1378/chest.121.3.976 PMID: 11888985

10. Larson JL, Lambert L, Stricof RL, Driscoll J, McGarry MA, Ridzon R. Potential nosocomial exposure to Mycobacterium tuberculosis from a bronchoscope.Infect Control Hosp Epidemiol. 2003;24(11):825-30. DOI: 10.1086/502144 PMID: 14649770

11. Kressel AB, Kidd F. Pseudo-outbreak of Mycobacterium chelonae and Methylobacterium mesophilicum caused by contamination of an automated endoscopy washer. Infect Control Hosp Epidemiol. 2001;22(7):414-8. DOI: 10.1086/501926 PMID: 11583208

12. Wang HC, Liaw YS, Yang PC, Kuo SH, Luh KT. A pseudoepidemic of Mycobacterium chelonae infection caused by contamination of a fibreoptic bronchoscope suction channel.Eur Respir J. 1995;8(8):1259-62. DOI: 10.1183/09031936.95.08081259 PMID: 7489787

13. Kirschke DL, Jones TF, Craig AS, Chu PS, Mayernick GG, Patel JA, et al. Pseudomonas aeruginosa and Serratia marcescens contamination associated with a manufacturing defect in bronchoscopes. N Engl J Med. 2003;348(3):214-20. DOI: 10.1056/NEJMoa021791 PMID: 12529461

14. Silva CV, Magalhães VD, Pereira CR, Kawagoe JY, Ikura C, Ganc AJ. Pseudo-outbreak of Pseudomonas aeruginosa and Serratia marcescens related to bronchoscopes. Infect Control Hosp Epidemiol. 2003;24(3):195-7. DOI: 10.1086/502195 PMID: 12683511

15. Rosengarten D, Block C, Hidalgo-Grass C, Temper V, Gross I, Budin-Mizrahi A, et al. Cluster of pseudoinfections with Burkholderia cepacia associated with a contaminated washer-disinfector in a bronchoscopy unit. Infect Control Hosp Epidemiol. 2010;31(7):769-71. DOI: 10.1086/653611 PMID: 20470036

16. Cêtre JC, Salord H, Vanhems P. Outbreaks of infection associated with bronchoscopes.N Engl J Med. 2003;348(20):2039-40, author reply 2039-40. DOI: $10.1056 /$ NEJM200305153482021 PMID: 12748325

17. Wheeler PW, Lancaster D, Kaiser AB. Bronchopulmonary cross-colonization and infection related to mycobacterial contamination of suction valves of bronchoscopes.J Infect Dis. 1989;159(5):954-8. DOI: 10.1093/infdis/159.5.954 PMID: 2708844

18. Bryce EA, Walker M, Bevan C, Smith JA. Contamination of bronchoscopes with Mycobacterium tuberculosis. Can J Infect Control. 1993;8(2):35-6.PMID: 8400340

19. Guideline for disinfection and sterilization in healthcare facilities, 2008. Atlanta: Centers for Disease Control and 
Prevention. [Accessed: January2015]. Available from:http:// www.cdc.gov/hicpac/Disinfection_Sterilization/3_odisinfectE quipment.html\#

20. Infection prevention and control guideline for flexible gastrointestinal endoscopy and flexible bronchoscopy. Ottawa: Public Health Agency of Canada; 2011. Available from: http:// www.phac-aspc.gc.ca/nois-sinp/guide/endo/index-eng.php

21. Comité Technique National des Infections Nosocomiales. [National Technical Committee of Nosocomial Infections]. Bonnes pratiques de désinfection des dispositifs médicaux. Guide pour l'utilisation des laveurs-désinfecteurs

d'endoscopes. [Good practice for disinfecting medical devices. Guide for the use of washer-disinfectors of endoscopes]. Paris: Ministère de la santé, de la famille et des personnes handicapées; 2003. French. Available from: http://socialsante.gouv.fr/IMG/pdf/Guide_pour_l_utilisation_des_laveurs_ desinfecteurs_d_endoscopes.pdf

22. Circulaire DHOS/E 2/DGS/SD $5 \mathrm{C} \mathrm{n}^{\circ}$ 2003-591 du 17 décembre 2003 relative aux modalités de traitement manuel pour la désinfection des endoscopes non autoclavables dans les lieux de soins. [Circular DHOS / 2 E / DGS / SD 5 C No. 2003591 of 17 December 2003 on manual processing procedures for the disinfection of non-autoclavable endoscopes in healthcare settings]. Paris: Direction de l'Hospitalisation et de l'Organisation des Soins (DHOS); 2003. French. Available from: http://social-sante.gouv.fr/fichiers/bo/2004/04-01/a0010011. htm

23. Avis. Enceintes de stockage d'endoscopes thermosensibles (ESET). [Opinion. Storage containers for thermosensitive endoscopes]. Paris: Haut Conseil de la santé publique; 2013. French. Available from: http://www.hcsp.fr/ Explore.cgi/Telecharger?NomFichier=hcspa20130626_ enceintestockendoscothermosens.pdf

24. Comité Technique des Infections Nosocomiales et des Infections Liées aux Soins. [National Technical Committee of Nosocomial and healthcare-associated Infections]. Eléments d'assurance qualité en hygiène relatifs au contrôle microbiologique des endoscopes et à la traçabilité en endoscopie. [Quality assurance elements in hygiene regarding microbiological testing of endoscopes and traceability in endoscopy]. Paris: Ministère de la santé et des solidarités, Direction Générale de la Santé/Direction de l'Hospitalisation et de l'Organisation des Soins; 2007. French. Available from: http://social-sante.gouv.fr/IMG/pdf/microbio_endoscopes-2. pdf

25. Cornaglia G, Courcol R, Herrmann JL. European manual of clinical microbiology. Basel: European Society for Clinical Microbiology and Infections Diseases, Sociétéfrançaise de microbiologie, 2012.

26. Cholley P, Gbaguidi-Haore H, Bertrand X, Thouverez M, Plésiat $P$, Hocquet $D$, et al. Molecular epidemiology of multidrugresistant Pseudomonas aeruginosa in a French university hospital. J Hosp Infect. 2010;76(4):316-9. DOI: 10.1016/j. jhin.2010.06.007 PMID: 20692070

27. Cosgrove SE, Ristaino P, Caston-Gaa A, Fellerman DP, Nowakowski EF, Carroll KC, et al. Caveat emptor: the role of suboptimal bronchoscope repair practices by a thirdparty vendor in a pseudo-outbreak of pseudomonas in bronchoalveolar lavage specimens. Infect Control Hosp Epidemiol. 2012;33(3):224-9. DOI: 10.1086/664051 PMID: 22314057

28. Stigt JA, Wolfhagen MJ, Smulders P, Lammers V. The Identification of Stenotrophomonas maltophilia Contamination in Ultrasound Endoscopes and Reproduction of Decontamination Failure by Deliberate Soiling Tests. Respiration. 2015;89(6):565-71. DOI: 10.1159/000381725 PMID: 25925975

\section{License and copyright}

This is an open-access article distributed under the terms of the Creative Commons Attribution (CC BY 4.0) Licence. You may share and adapt the material, but must give appropriate credit to the source, provide a link to the licence, and indicate if changes were made.

This article is copyright of the authors, 2016. 